\title{
High Prevalence of the SCN5A E1784K Mutation in School Children With Long QT Syndrome Living on the Okinawa Islands
}

\author{
Kazuhiro Takahashi, MD, PhD; Wataru Shimizu, MD, PhD; Akira Miyake, MD; \\ Taisuke Nabeshima, MD; Mami Nakayashiro, MD; Hitoshi Ganaha, MD
}

\begin{abstract}
Background: Genetic testing for long QT syndrome (LQTS) is now in clinical practice. We conducted molecular genetic analyses to definitively diagnose LQTS and to determine its subtypes for gene-specific treatment. We conducted a retrospective study to determine the characteristics of schoolchildren with LQTS living on the Okinawa Islands.
\end{abstract}

\begin{abstract}
Methods and Results: The study population included children identified in a school-based electrocardiographic (ECG) screening program for cardiovascular diseases who were referred to Okinawa Children's Medical Center between 2007 and 2012; 23 children met the diagnostic criteria for LQTS. Of them, 17 were genotype-positive and 14 were found to harbor the SCN5A E1784K mutation exclusively among the LQTS genotype-positive children. The children were divided into genotype-positive and -negative groups. Clinical characteristics and ECG data were analyzed and compared. The median Schwartz score was 3. The median QT interval was $521 \mathrm{ms.}$
\end{abstract}

Conclusions: The major finding is that the prevalent subtype of LQTS in Okinawa is discordant with other cohorts living in other regions of Japan or overseas. We cannot exclude the possibility of the presence of a specific founder mutation in this geographically clustered population, particularly considering that the hospital is the only tertiary heart center for children in Okinawa. However, this uniquely high prevalence of the SCN5A E1784K mutation serves as a compelling justification to conduct a larger study. (Circ J 2014; 78: 1974-1979)

Key Words: Arrhythmia; Long QT syndrome; Okinawa; SCN5A

$\mathbf{T}$ he long QT syndrome (LQTS) is an inherited disorder of cardiac repolarization characterized by electrocardiographic (ECG) abnormalities, syncopal attacks, and risk of sudden death from ventricular tachyarrhythmias such as torsade de pointes. ${ }^{1,2}$ Mutations in genes encoding cardiac ion channels and membrane adaptor proteins cause this syndrome. There are 13 distinct LQTS-susceptibility genes and mutations in the 3 most common LQTS subtypes (KCNQ1mediated LQT1, $K C N H 2$-mediated LQT2, and $S C N 5 A$-mediated LQT3) account for approximately $80 \%$ of clinically confirmed cases of LQTS. ${ }^{3-5}$

\section{Editorial $p 1839$}

Genotyping is used for adjunctive diagnosis as well as for gene-specific risk stratification and gene-specific therapy, particularly for LQTS. ${ }^{5-8}$ We report here the overrepresentation of the LQT3 mutation detected by genetic testing conducted at a regional tertiary children's medical center on the Okinawa Islands of Japan, and describe the children's clinical characteristics and outcomes.

\section{Methods}

\section{Patient Recruitment}

Okinawa Children's Medical Center is the only tertiary hospital for children on the Okinawa Islands of Japan. It serves 1.4 million people and is a regional referral center that offers a comprehensive clinical practice of pediatric cardiology. A school-based ECG screening program for cardiovascular diseases aimed at schoolchildren in the 1st, 7th, and 10th grades is conducted all over Japan to identify heart problems. Schoolchildren are also checked for clinical and familial findings associated with LQTS, such as syncope, congenital deafness, and unexplained sudden cardiac death among family members. Children with positive findings are directed to referral

Received December 16, 2013; revised manuscript received April 15, 2014; accepted April 20, 2014; released online May 28 , 2014 Time for primary review: 22 days

Department of Pediatric Cardiology, Okinawa Children's Medical Center, Okinawa (K.T., A.M., T.N., M.N., H.G.); Department of Cardiovascular Medicine, Nippon Medical School, Tokyo (W.S.), Japan

Mailing address: Kazuhiro Takahashi, MD, PhD, Department of Pediatric Cardiology, Okinawa Children's Medical Center, 118-1 Arakawa, Haebaru, Okinawa 901-1193, Japan. E-mail: bigkaz@mua.biglobe.ne.jp

ISSN-1346-9843 doi:10.1253/circj.CJ-13-1516

All rights are reserved to the Japanese Circulation Society. For permissions, please e-mail: cj@j-circ.or.jp 


\begin{tabular}{|c|c|c|c|c|}
\hline & Total & Gene positive & Gene negative & $P$ value \\
\hline $\mathrm{n}$ & 23 & 17 & 6 & \\
\hline Age at 1 st referral (years) & $9.7 \pm 3.4$ & $9.4 \pm 3.6$ & $10.8 \pm 3.4$ & NS \\
\hline $\operatorname{Sex}(M / F)$ & $15 / 8$ & $11 / 6$ & $4 / 2$ & NS \\
\hline Follow-up duration, months & $37 \pm 23$ & $43 \pm 23$ & $23 \pm 14$ & NS \\
\hline
\end{tabular}

Data given as mean \pm SD. LQTS, long QT syndrome.

hospitals..$^{9,10}$

The present study population was retrospectively recruited from children who participated in the school-based ECG screening program and were referred to Okinawa Children's Medical Center between April 2007 and March 2013. The diagnosis of LQTS and screening for prolonged QT intervals was based on the judgment of the physician in each hospital that participated in the program in each area. For their final diagnosis, many physicians use a scoring system published in $1993 .{ }^{11}$ Included were children who met the diagnostic criteria for LQTS ("Schwartz and Moss" score $\geq 3$ ). This approach is similar to that described in a published study, ${ }^{5}$ although the most recent HRS/EHRA/APHRS expert consensus statement recommends that the score is $\geq 3.5 .^{12}$

Retrospective review was approved by the Institutional Review Board. The patients' characteristics that were reviewed included sex, age at diagnosis, presence or absence of syncope, seizures, aborted cardiac arrest, family history, and 12-lead ECG. We assigned a cumulative LQTS diagnostic score, which is derived in part from the corrected QT interval (QTc), symptoms, and family history. ${ }^{11}$ The children were divided into genotype-positive and -negative subgroups (G-pos and G-neg) according to the results of genetic analysis. Clinical characteristics and ECG data were analyzed and compared between the subgroups.

\section{Clinical Testing}

Each patient referred to the center for the evaluation of LQTS had their history taken and underwent a physical examination and a supine ECG. The QT interval was measured with a standard 12-lead ECG using lead V5. The ECG measurements were conducted by K. T. who was blinded to each subject's genetic status before making the measurements. QT interval was measured manually and defined as the time interval between QRS onset and the point at which the isoelectric baseline intersected a tangential line drawn at the maximal downslope of the positive T wave. QT interval measurements represented the mean of 3 consecutive beats in lead V5. The QT interval was corrected for rate using the Bazett formula $(\mathrm{QT} / \sqrt{\mathrm{RR}}$, interval measured in seconds). The LQTS score was determined according to the LQTS diagnostic criteria described earlier. Diagnostic criteria included the QTc interval $(450 \mathrm{~ms})$, at least 1 symptomatic episode (bradycardia), or a family history of LQTS. A cumulative score $\geq 3$ suggested an intermediate probability of LQTS.

\section{Genetic Testing}

Genetic testing was recommended according to the opinion of the chief physician who participated in the present study, and it was performed when the phenotype suggested LQTS according to the Schwartz score and clinical presentation or as detailed in the recent consensus report. ${ }^{12}$ After written informed consent was given, genomic DNA was isolated from blood for

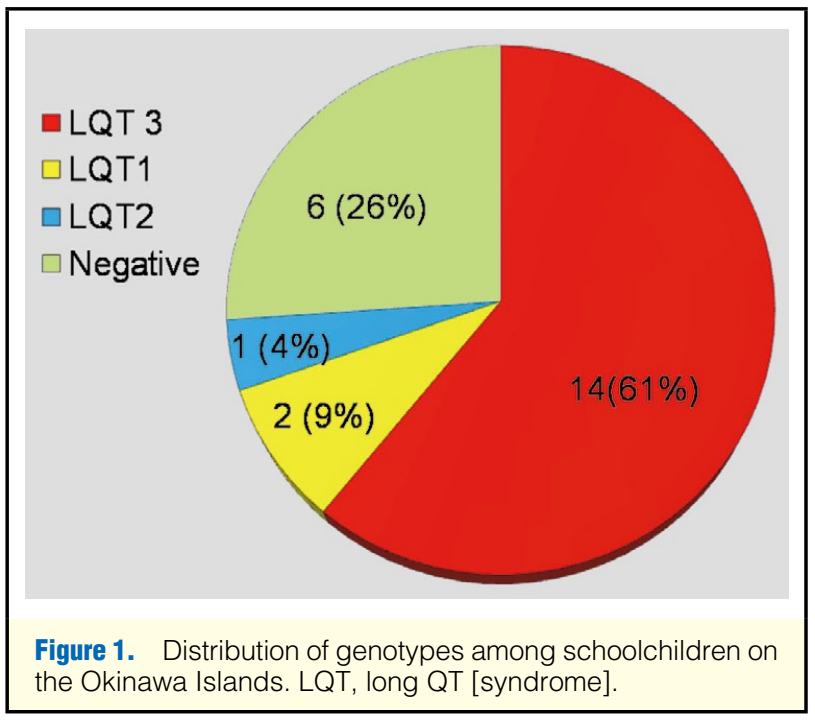

direct sequencing of the complete $K C N Q 1, K C N H 2$ and $S C N 5 A$ genes in the National Cerebral and Cardiovascular Center, Osaka, Japan.

\section{Statistical Analysis}

The values of the continuous variables are presented as the mean \pm standard deviation or median and interquartile range. Categorical variables are represented by frequencies and percentages. Data were compared between the 2 groups using the following tests: t-test for normally distributed continuous variables, Mann-Whitney test for non-normally distributed data, and the chi-square or Fisher's exact test to compare the frequency distribution of categorical variables. Two-tailed $\mathrm{P}<0.05$ was considered statistically significant. Analyses were performed using StatView J-5.0 PPC (SAS Institute Inc, Cary, NC, USA).

\section{Results}

\section{Study Population}

The study population comprised 23 children who met the criteria during the study period. Demographic data at referral are shown in Table 1.

A total of 17 (74\%) children were positive in genetic testing (G-pos subgroup; 6 females) and 6 were negative (G-neg subgroup, 2 females). Mean age at referral was $9.7 \pm 3.4$ years. Total follow-up period for the G-pos and G-neg groups was $43 \pm 23$ months and $23 \pm 14$ months, respectively. Figure 1 shows the distribution of genotypes. The G-pos subgroup comprised LQT type 1 (LQT1, n=2), LQT type 2 (LQT2, 


\begin{tabular}{|c|c|c|c|c|}
\hline & Total & Gene positive & Gene negative & $P$ value \\
\hline \multicolumn{5}{|l|}{ ECG findings } \\
\hline Average QTc (ms) & $510 \pm 44$ & $516 \pm 45$ & $495 \pm 39$ & NS \\
\hline$\% \mathrm{w} / \mathrm{QTc}>480 \mathrm{~ms}$ & $15(65 \%)$ & $12(71 \%)$ & $3(50 \%)$ & NS \\
\hline$\%$ w/Schwartz score $\geq 4$ & $8(35 \%)$ & $6(35 \%)$ & $2(33 \%)$ & NS \\
\hline Late-appearing $T$ wave & $15(65 \%)$ & $14(82 \%)$ & $1(17 \%)$ & $<0.01$ \\
\hline \multicolumn{5}{|l|}{ Symptoms } \\
\hline Syncope, $n$ & 1 & 0 & 1 & NS \\
\hline Bradycardia, $\mathrm{n}$ & 1 & 1 & 0 & NS \\
\hline Epilepsy & 1 & 0 & 1 & NS \\
\hline \multicolumn{5}{|l|}{ Family history } \\
\hline Positive for LQTS, $n$ & $8(35 \%)$ & $7(41 \%)$ & $1(17 \%)$ & NS \\
\hline
\end{tabular}

ECG, electrocardiographic; LQTS, long QT syndrome; QTc, corrected QT interval.

\begin{tabular}{|c|c|c|c|c|}
\hline & Total & Gene positive & Gene negative & $P$ value \\
\hline \multicolumn{5}{|l|}{ Symptoms } \\
\hline Syncope/presyncope, n (\%) & $3(13)$ & $2(12)$ & $1(17)$ & NS \\
\hline Bradycardia, $\mathrm{n}$ & 4 & 2 & 2 & NS \\
\hline Epilepsy, n & 2 & 1 & 1 & NS \\
\hline \multicolumn{5}{|l|}{ Treatment } \\
\hline Medications, n (\%) & $9(39)$ & $7(41)$ & $2(33)$ & NS \\
\hline Mex, $n$ & 8 & 7 & 1 & \\
\hline $\mathrm{BB}, \mathrm{n}$ & 3 & 3 & 0 & \\
\hline Antiepileptic, $n$ & 2 & 1 & 1 & \\
\hline Pacemaker, $\mathrm{n}$ & 1 & 1 & 0 & NS \\
\hline
\end{tabular}

BB, $\beta$-blocker; LQTS, long QT syndrome; Mex, mexiletine.

$\mathrm{n}=1$ ), and LQT type 3 (LQT3, n=14). LQT3 was the most prevalent subtype (82\%) in the G-pos subgroup. Further, all patients with LQT3 were found to share the same $S C N 5 A$ c. $5350 \mathrm{G}>\mathrm{A}$ p.E1784K mutation within the sequence that encodes the transmembrane region of the SCN5A sodium ion channel.

\section{ECG Data and Clinical Characteristics at Referral}

Clinical and ECG data of the subgroups were analyzed, and the comparisons are shown in Table 2. The average QTc interval was $510 \mathrm{~ms}(516 \mathrm{~ms}$ vs. $495 \mathrm{~ms}$, NS). The frequency of patients with QTc $>480 \mathrm{~ms}$ and with a Schwarz and Moss score $>4$ was not significantly different between the groups.

Although the findings were somewhat subjective for QT morphology, late-appearing $\mathrm{T}$ wave was more frequent in the G-pos subgroup ( $82 \%$ vs. $17 \%, \mathrm{P}<0.01)$. There was no Brugada syndrome (BrS)-type ECG in the cohort at referral. No provocative test with sodium-channel blockers was performed. Each child was asymptomatic at presentation except for 1 in the G-neg subgroup; 1 child in the G-pos subgroup exhibited sinus bradycardia, and 1 child in the G-neg subgroup was epileptic. All but 2 children were unrelated. To the best of our knowledge, all parents of the probands were descendants of the Okinawa Islands. There was no identifiable common relative for this cohort after pedigree construction. A familial history of LQT was identified in $35 \%$ of the children, and its presence trended toward an increase among the G-pos chil- dren compared with the G-neg children ( $41 \%$ vs. $17 \%$ ). Pacemakers were implanted in selected children based on screening of their first-degree relatives (unpublished data).

\section{Clinical Outcome and Treatment During Follow-up}

During the study period, no child died from sudden cardiac arrest, although syncope or presyncope occurred ( $n=2$ vs. $n=1$, NS) (Table 3). One child in each subgroup developed epilepsy, which was diagnosed using electroencephalography. Treatment with an antiepileptic drug controlled their symptoms, and 1child was the subject of another report. ${ }^{13}$ Two children experienced bradycardia on Holter monitoring, and 1 child in the G-pos group required pacemaker therapy for symptomatic sick sinus syndrome. The detailed clinical features of patients with newly developed symptoms during the follow-up period are presented in Table 4.

Treatment Nine (39\%) of 23 patients received pharmacotherapy ( 7 and 2 in the G-pos and G-neg subgroups, respectively). The indication for pharmacotherapy in asymptomatic LQTS patients considered at high risk is QTc $>500 \mathrm{~ms}$, if the patient also agrees to keep taking the medication. One patient in each group received an antiepileptic agent. Mexiletine was administered to 7 patients in the G-pos subgroup (with $\beta$-blockers for 3 ) and 1 in the G-neg subgroup without $\beta$-blocker.

In the G-pos subgroup, QTc significantly decreased (from $553 \mathrm{~ms}$ to $491 \mathrm{~ms} ; \mathrm{P}=0.02$ ) in the 7 patients receiving mexi- 


\begin{tabular}{|c|c|c|c|c|c|c|c|}
\hline Subtype & $\begin{array}{c}\text { Age } \\
\text { (years) }\end{array}$ & Sex & Gene test & $\begin{array}{l}\text { QTc at referral } \\
\text { (ms) }\end{array}$ & $\begin{array}{l}\text { QTc at follow-up } \\
\text { (ms) }\end{array}$ & Symptoms & $\begin{array}{l}\text { Cardiovascular } \\
\text { treatment }\end{array}$ \\
\hline G-pos & 13 & $\mathrm{~F}$ & KCNQ1 & 531 & 524 & $\begin{array}{l}\text { Resuscitation } \\
\text { drowning }\end{array}$ & Mex, BB \\
\hline G-pos & 17 & $\mathrm{~F}$ & E1784K & 591 & 502 & Syncope VT & $\begin{array}{l}\text { Mex, BB, } \\
\text { pacemaker }\end{array}$ \\
\hline G-pos & 11 & $\mathrm{~F}$ & E1784K & 565 & 423 & Epilepsy & Mex \\
\hline G-neg & 12 & M & Negative & 556 & 553 & $\begin{array}{l}\text { Syncope with } \\
\text { exertion }\end{array}$ & Mex \\
\hline G-neg & 10 & M & Negative & 492 & 505 & Epilepsy & No \\
\hline
\end{tabular}

VT, ventricular arrhythmia. Other abbreviations as in Tables 2,3.

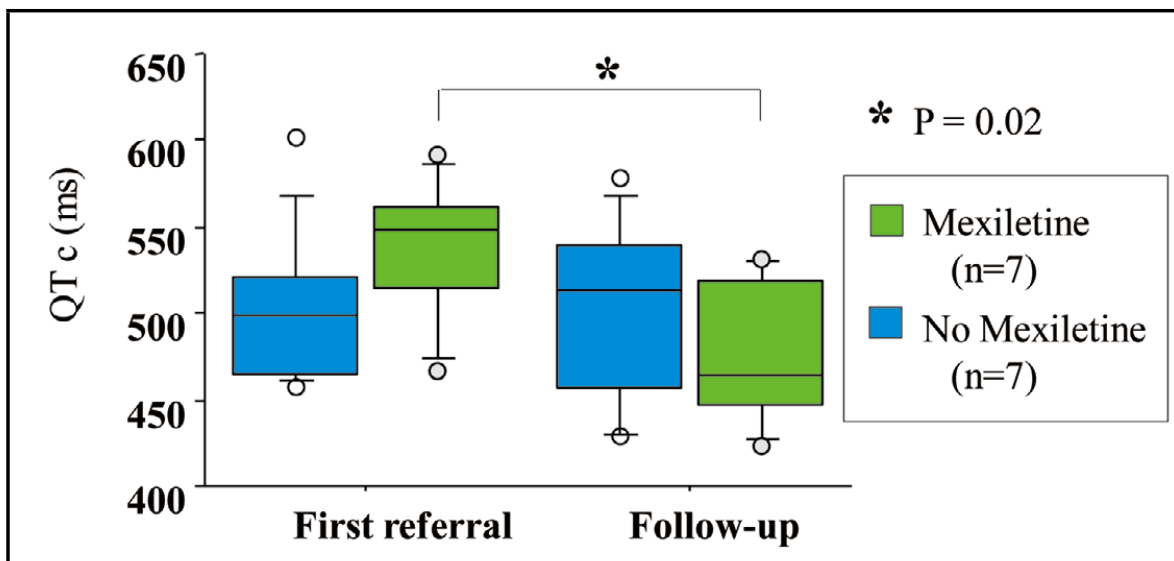

Figure 2. Changes in the corrected QT intervals (QTc) of pediatric patients in the subgroup positive for the E1784K mutation and receiving mexiletine. letine, whereas the change in QTc (from $497 \mathrm{~ms}$ to $508 \mathrm{~ms}$ ) was not significant in the 7 patients receiving no medication (Figure 2). All but 1 child on medication in the G-pos group showed no BrS-type ECG on the third-right precordial leads.

\section{Discussion}

The most significant finding of this retrospective study of a small cohort is that the proportion of patients with LQT3 with the $S C N 5 A$ mutation was significantly higher than previously reported for patients living in other regions of Japan or in other countries. Further, the course of LQTS probands with the E1784K mutation was relatively benign during the study period.

\section{Prevalence of LQT3}

The children referred to us were screened according to the judgment of the physicians who participated in the program in each area. Therefore, the exact number of the entire population of participants in this study is unknown. According to another study, the prevalence of long QT was 1 in 1,164 among 7 th graders aged 12 years. ${ }^{14}$

In general, approximately $90 \%$ of patients with genotyped LQTS carry a mutation in KCNQ1, KCNH2 (HERG), or $S C N 5 A$, which is responsible for the LQTS subtype..$^{5,8}$ The most prevalent form of LQTS appears to be caused by mutations in $K C N Q 1$, which encodes the potassium channel (LQT1). ${ }^{7,9,10,15}$ Mutations in SCN5A (LQT3) are responsible for only a small proportion (10-20\%) of genotyped patients with LQTS. ${ }^{16,17}$ In sharp contrast to these previous findings, the present study describes a predominance of LQT3 (82\% of genotyped patients with LQTS) among schoolchildren living on the Okinawa Islands. Even more striking is the exclusive presence of the SCN5A E1784K mutation that causes LQT3. Yoshinaga et al ${ }^{9}$ recently reported the genetic characteristics of children and adolescents with LQTS diagnosed by school-based ECG screening programs. The incidence of LQT3 was $23 \%$ of all subjects in that study population with LQTS. An E1784K mutation was detected only in 1 patient. Blaufox et al published a multicenter study of patients residing in North America that showed that an E1784K mutation is present in $13(30 \%)$ of 43 pediatric patients with LQT3. ${ }^{18}$

In patients with the $S C N 5 A$ E1784K mutation, overlap of sinus node dysfunction and $\mathrm{BrS}$ is relatively common. ${ }^{19} \mathrm{Re}-$ garding the prevalence of LQT3 in other Asian countries such as Taiwan, China, and South Korea, we speculate that the high prevalence of LQT3 is similar to that of BrS in Asia. ${ }^{20}$ To the best of our knowledge, only a limited number of reports have addressed the prevalence of LQT3 in Asian countries. For example, the SCN5A mutation was detected in $17.5 \%$ of all genotyped patients with LQTS residing in South Korea. ${ }^{21}$ The mutation rate of $\mathrm{KCNQ1}(6.4 \%)$ and $\mathrm{KCNH} 2(6.4 \%)$ was lower in the Chinese population compared with those of North America or Europe. ${ }^{22}$ The true prevalence of LQT3 in Asia is unknown, but we believe that it is reasonable to conclude that LQT3 may be prevalent in China.

The high prevalence of LQT3 in Okinawa may be accounted for, in part, by the potential bias introduced by studying a small number of patients at a single center. A second possible cause is a founder mutation, which is defined as disproportion- 
ate genetic representation resulting from an affected common ancestor who established a new population, in contrast to the presence of the same mutation among individuals. Such a regional predominance in frequency is associated with LQT1. ${ }^{23-25}$ There is a report that describes a large Dutch family with a founder mutation that uniquely overlaps those of LQT3, BrS, and progressive cardiac conduction defects. ${ }^{26}$

The subtropical Okinawa Islands are located 2,000 km south of mainland Japan between the East China Sea and the Pacific Ocean. Although haplotype analysis was not performed, a common ethnic heritage for the inhabitants of the Okinawa Islands is consistent with a founder effect. The study subjects described here are unrelated, except for 2 . Therefore, the predominant genotype of the children with LQTS studied here strongly suggests community clustering that may represent a founder effect of the same SCN $5 A$ mutation.

\section{Clinical Characteristics of Patients and Their Treatment}

In the present study, most patients were asymptomatic at initial diagnosis, and the disease may have been relatively benign at this time. However, 2 patients experienced bradycardia during the follow-up period, and 1 required implantation of a pacemaker. Zareba et al reported that a cardiac event will occur after adolescence in patients with LQT3. ${ }^{27}$ The symptoms of patients with LQT3 generally appear after puberty, and in BrS, the electrophysiological phenotype is most prevalent in the 3rd decade. The developmental characteristics of LQT3 and BrS show age-dependent penetrance. ${ }^{28}$ The late presentation and frequent asymptomatic status of carriers is consistent with a benign disease with possible post-reproductive pathogenicity in the population of the Okinawa Islands.

To date, 8 of 15 patients in the present study received mexiletine. Only 1 patient exhibited a BrS-type ECG while taking this medication. Bradycardia was detected using the third rightprecordial lead in the single patient with a BrS-type ECG. Patients with LQT3 without cardiac events in the first year of life respond extremely well to therapy with $\beta$-blockers, left cervical sympathetic denervation, or both. ${ }^{29}$ Mexiletine is considered the medication of choice for treating LQT3. ${ }^{30,31}$ However, 2 studies recommend caution when treating LQT3 because a patient's response depends on the type of mutation..$^{32,33}$ Further, an in-vivo study showed that patients with the SCN5A E1784K mutation respond to mexiletine. ${ }^{19}$ The diagnosis of LQT3 does not necessarily indicate treatment with an implantable cardioverter-defibrillator. For this reason, Schwartz et al recommend a staged strategy. ${ }^{29}$

\section{Study Limitations}

This was a small and retrospective cohort study. Although the study groups should include patients with LQT3 as well as those positive and negative for mutation, the distribution of the prevalence of genotype-positive subtypes was unpredictably imbalanced and unique. The prevalence of LQT3 (exclusively the E1784K mutation) was predominantly high in genotype-positive patients; therefore, we conclude that our classification was justified. Moreover, despite the possibility of the enrollment of patients with a specific founder mutation and considering that the hospital is the only tertiary heart center for children in Okinawa, our findings of a unique and highly prevalent SCN5A mutation (E1784K) serve as a compelling justification to conduct larger or long-term studies.

\section{Conclusions}

We were unable to determine why the prevalence of the SCN5A
E1784K mutation was uniquely high among schoolchildren living on the Okinawa Islands. The prognosis of these patients is relatively benign; however, the prognosis for adults is unknown. Because of the geography of Okinawa, its population should be ideal for studies on gene modifiers with a focus on the prevalent $S C N 5 A$ mutation.

\section{References}

1. Schwartz PJ, Periti M, Malliani A. The long Q-T syndrome. Am Heart J 1975; 89: 378-390.

2. Moss AJ, Schwartz PJ, Crampton RS, Tzivoni D, Locati EH, MacCluer $\mathrm{J}$, et al. The long QT syndrome: Prospective longitudinal study of 328 families. Circulation 1991; 84: 1136-1144.

3. Napolitano C, Priori SG, Schwartz PJ, Bloise R, Ronchetti E, Nastoli $\mathrm{J}$, et al. Genetic testing in the long QT syndrome: Development and validation of an efficient approach to genotyping in clinical practice. JAMA 2005; 294: 2975-2980.

4. Shimizu W. Update of diagnosis and management of inherited cardiac arrhythmias. Circ J 2013; 77: 2867-2872.

5. Schwartz PJ, Crotti L, Insolia R. Long-QT syndrome: From genetics to management. Circ Arrhythm Electrophysiol 2012; 5: 868-877.

6. Tester DJ, Will ML, Haglund CM, Ackerman MJ. Effect of clinical phenotype on yield of long QT syndrome genetic testing. J Am Coll Cardiol 2006; 47: 764-768.

7. Priori SG, Schwartz PJ, Napolitano C, Bloise R, Ronchetti E, Grillo $\mathrm{M}$, et al. Risk stratification in the long-QT syndrome. $N$ Engl $\mathrm{J}$ Med 2003; 348: 1866-1874.

8. Moss AJ, Goldenberg I. Importance of knowing the genotype and the specific mutation when managing patients with long QT syndrome. Circ Arrhythm Electrophysiol 2008; 1: 213-226.

9. Yoshinaga M, Kucho Y, Sarantuya J, Ninomiya Y, Horigome H, Ushinohama $\mathrm{H}$, et al. Genetic characteristics of children and adolescents with long-QT syndrome diagnosed by school-based electrocardiographic screening programs. Circ Arrhythm Electrophysiol 2014; 7: $107-112$.

10. Hayashi K, Fujino N, Uchiyama K, Ino H, Sakata K, Konno T, et al. Long QT syndrome and associated gene mutation carriers in Japanese children: Results from ECG screening examinations. Clin Sci (Lond) 2009; 117: 415-424.

11. Schwartz PJ, Moss AJ, Vincent GM, Crampton RS. Diagnostic criteria for the long QT syndrome: An update. Circulation 1993; 88: $782-784$.

12. Priori SG, Wilde AA, Horie M, Cho Y, Behr ER, Berul C, et al. HRS/EHRA/APHRS expert consensus statement on the diagnosis and management of patients with inherited primary arrhythmia syndromes: Document endorsed by HRS, EHRA, and APHRS in May 2013 and by ACCF, AHA, PACES, and AEPC in June 2013. Heart Rhythm 2013; 10: 1932-1963.

13. Takahashi K, Miyake A, Otsuka Y, Ohfu M, Ganaha H. Diagnosis of epilepsy using an implantable loop recorder in a child with longQT syndrome type 3. Pediatr Int 2013; 55: 251-253.

14. Fukushige T, Yoshinaga M, Shimago A, Nishi J, Kono Y, Nomura $\mathrm{Y}$, et al. Effect of age and overweight on the QT interval and the prevalence of long QT syndrome in children. Am J Cardiol 2002; 89: 395-398.

15. Moss AJ, Shimizu W, Wilde AA, Towbin JA, Zareba W, Robinson $\mathrm{JL}$, et al. Clinical aspects of type-1 long-QT syndrome by location, coding type, and biophysical function of mutations involving the KCNQ1 gene. Circulation 2007; 115: 2481-2489.

16. Tester DJ, Will ML, Haglund CM, Ackerman MJ. Compendium of cardiac channel mutations in 541 consecutive unrelated patients referred for long QT syndrome genetic testing. Heart Rhythm 2005; 2: 507-517.

17. Kapplinger JD, Tester DJ, Salisbury BA, Carr JL, Harris-Kerr C, Pollevick GD, et al. Spectrum and prevalence of mutations from the first 2,500 consecutive unrelated patients referred for the FAMILION long QT syndrome genetic test. Heart Rhythm 2009; 6: 1297-1303.

18. Blaufox AD, Tristani-Firouzi M, Seslar S, Sanatani S, Trivedi B, Fischbach P, et al. Congenital long QT 3 in the pediatric population. Am J Cardiol 2012; 109: 1459-1465.

19. Makita N, Behr E, Shimizu W, Horie M, Sunami A, Crotti L, et al. The E1784K mutation in SCN5A is associated with mixed clinical phenotype of type 3 long QT syndrome. J Clin Invest 2008; 118: 2219-2229.

20. Murakoshi N, Aonuma K. Epidemiology of arrhythmias and sudden cardiac death in Asia. Circ J 2013; 77: 2419-2431.

21. Lee YS, Kwon BS, Kim GB, Oh SI, Bae EJ, Park SS, et al. Long QT syndrome: A Korean single center study. J Korean Med Sci 2013; 
28: $1454-1460$.

22. Liu W, Hu D, Li C, Li P, Li Y, Li Z, et al. Mutation analysis of potassium channel genes KCNQ1 and $\mathrm{KCNH} 2$ in patients with long QT syndrome. Chin Med J (Engl) 2003; 116: 1333-1335.

23. Gray C, Gula LJ, Klein GJ, Skanes AC, Yee R, Sy R, et al. Expression of a common LQT1 mutation in five apparently unrelated families in a regional inherited arrhythmia clinic. J Cardiovasc Electrophysiol 2010; 21: 296-300.

24. Fodstad H, Swan H, Laitinen P, Piippo K, Paavonen K, Viitasalo M, et al. Four potassium channel mutations account for $73 \%$ of the genetic spectrum underlying long-QT syndrome (LQTS) and provide evidence for a strong founder effect in Finland. Ann Med 2004; 36: $53-63$.

25. Piippo K, Swan H, Pasternack M, Chapman H, Paavonen K, Viitasalo $\mathrm{M}$, et al. A founder mutation of the potassium channel KCNQ1 in long QT syndrome: Implications for estimation of disease prevalence and molecular diagnostics. J Am Coll Cardiol 2001; 37: 562-568.

26. Postema PG, Van den Berg M, Van Tintelen JP, Van den Heuvel F, Grundeken M, Hofman N, et al. Founder mutations in the Netherlands: SCN5a 1795insD, the first described arrhythmia overlap syndrome and one of the largest and best characterized families worldwide. Neth Heart J 2009; 17: 422-428.

27. Zareba W, Moss AJ, Schwartz PJ, Vincent GM, Robinson JL, Priori $\mathrm{SG}$, et al. Influence of genotype on the clinical course of the long-QT syndrome: International Long-QT Syndrome Registry Research Group.
N Engl J Med 1998; 339: 960-965.

28. Beaufort-Krol GC, van den Berg MP, Wilde AA, van Tintelen JP, Viersma JW, Bezzina CR, et al. Developmental aspects of long QT syndrome type 3 and Brugada syndrome on the basis of a single SCN5A mutation in childhood. J Am Coll Cardiol 2005; 46: 331 337.

29. Schwartz PJ, Spazzolini C, Crotti L. All LQT3 patients need an ICD: True or false? Heart Rhythm 2009; 6: 113-120.

30. Schwartz PJ, Priori SG, Locati EH, Napolitano C, Cantù F, Towbin JA, et al. Long QT syndrome patients with mutations of the SCN5A and HERG genes have differential responses to $\mathrm{Na}^{+}$channel blockade and to increases in heart rate: Implications for gene-specific therapy. Circulation 1995; 92: 3381-3386.

31. Shimizu W, Antzelevitch C. Sodium channel block with mexiletine is effective in reducing dispersion of repolarization and preventing torsade des pointes in LQT2 and LQT3 models of the long-QT syndrome. Circulation 1997; 96: 2038-2047.

32. Ruan Y, Liu N, Bloise R, Napolitano C, Priori SG. Gating properties of SCN5A mutations and the response to mexiletine in long-QT syndrome type 3 patients. Circulation 2007; 116: 1137-1144.

33. Ruan Y, Denegri M, Liu N, Bachetti T, Seregni M, Morotti S, et al. Trafficking defects and gating abnormalities of a novel SCN5A mutation question gene-specific therapy in long QT syndrome type 3. Circ Res 2010; 106: 1374-1383. 